\title{
FLT3 - ITD positive acute lymphocytic leukemia, does it impact on disease 's course?
}

\author{
FLT3 - ITD pozitif akut lenfositik lösemi hastalığının gidişatını etkiliyebilir mi?
}

\author{
Sebastian Kobold1 ${ }^{1}$ Nerbil Kılıç1,2, J ohn Scharlau³ ${ }^{3}$ Carsten Bokemeyer ${ }^{1}$, Walter Fiedler ${ }^{1}$ \\ ${ }^{1}$ Department of Oncology/Hematology/Bone Marrow Transplantation with the Section Pneumology, University Medical \\ Center Hamburg Eppendorf, Hamburg, Germany \\ 2University Hospital Basel, Medical Oncology/Gynaecology, Basel, Switzerland \\ ${ }^{3}$ Clinic For Internal Medicine 2, University Hospital Bonn, Bonn, Germany
}

\section{To the Editor,}

Fms- like tyrosine kinase 3 (FLT3) - internal tandem duplication (ITD) has been identified in up to $25 \%$ of all acute myeloid leukemia where it correlates with a very poor prognosis [1]. Since FLT3 is frequently expressed by acute lymphocytic leukemia (ALL) blasts, activating FLT3 mutations may as well occur in this disease [2]. According to the literature, only 14 of 1634 ALL-patients were tested positive for FLT3-ITD (Table 1) [2-8]. Unfortunately, survival data of those patients is lacking and conclusions on the impact of FLT3-ITD in ALL patients are inconsistent. However - in analogy to AMLit has been suggested that FLT3-ITD dramatically worsens patient's survival [8].
We report of a 42-year-old woman with a FLT3-ITD PCR positive common B-ALL. No established negative prognostic factors were found; therefore the patient was considered at standard risk. The patient achieved a complete remission after the first course of conventional induction chemotherapy. Importantly, assessment of a patient specific molecular minimal residual disease (MRD) by PCR was repeatedly performed and scored negative. Since the first control at day 28 , none of the patient specific markers could be detected. 8 months later, the patient is still in complete remission. Accordingly, FLT3-ITD might not necessarily be associated with a worse outcome.

Interestingly, for all FLT3-ITD positive ALL patients where an adverse outcome had been described, other

Table 1. Overview on studies reporting FLT3-ITD- positive ALL patients and their outcome

\begin{tabular}{lccccc}
\hline \#patients screened & Study population & \#FLT3-ITD + & Risk factors & Outcome & Reference \\
\hline 60 & adults & 4 & high LDH, high blast count & $73.7 \%$ vs $84 \% *$ complete remissions & {$[2]$} \\
132 & children & 1 & relapsed ALL & N.S. & {$[3]$} \\
60 & children & 2 & biphenotypic ALL & 44 and 72 months & {$[9]$} \\
174 & children & 1 & none & alive at time of report & {$[5]$} \\
143 & children & 2 & N.S. & N.S. & {$[6]$} \\
63 & N.S. & 2 & biphenotypic ALL, high blast count & poor & {$[7]$} \\
449 & adults & 2 & CD117 positive & N.S. & {$[8]$} \\
\hline
\end{tabular}

*: FLT3+ vs FLT3- N.S.: not specified 
negative prognostic factors such as bi-phenotypic leukemia + [7, 9], c-Kit expressing T-ALL [8] or relapsed ALL [3] have been reported. Several authors even reported no deterioration of overall survival for FL3-ITD positive standard risk ALL patients (Table 1). In addition, it has been proposed that the prognosis might be correlated with high levels of FLT3 on leukemic blasts rather than with FLT3-ITD in ALL patients [2].

In the present case of a patient with common B-ALL, FLT3ITD did not seem to impact the patient's prognosis. This assumption is based on the persistently negative MRD assessment more than 8 months after treatment's start. A negative MRD on week 10 most strongly correlates with a prolonged remission and cure [10]. In fact, the MRD negative group has a projected $75 \%$ cure rate [10].

In summary, ALL with FLT3/ITD might not be associated with a poor prognosis, although the very low incidence of this molecular alteration in ALL prevents a definite conclusion. Larger prospective series are necessary to finally clarify the prognostic significance of FLT3 mutations in ALL.

\section{References}

1. Kottaridis PD, Gale RE, Linch DC. Prognostic implications of the presence of FLT3 mutations in patients with acute myeloid leukemia. Leuk Lymphoma 2003;44:905-13.

2. Peng $H L$, Zhang GS, Gong FJ, Shen J K, Zhang $Y, X u Y X$, Zheng WL, Dai CW, Pei MF, Yang JJ. Fms-like tyrosine kinase (FLT) 3 and FLT3 internal tandem duplication in different types of adult leukemia: analysis of 147 patients. Croat Med J 2008;49:650-69.

3. Wellmann $S$, Moderegger $E$, Zelmer $A$, Bettkober $M$, von Stackelberg A, Henze G, Seeger K. FLT3 mutations in childhood acute lymphoblastic leukemia at first relapse. Leukemia 2005;19:467-8.
4. Xu F, Taki T, Eguchi M, Kamada N, Ishii E, Endo M, Hayashi Y. Endo and Y. Hayashi. Tandem duplication of the FLT3 gene is infrequent in infant acute leukemia. J apan Infant Leukemia Study Group. Leukemia 2000;14:945-7.

5. Nakao M, J anssen J W, Erz D, Seriu T, Bartram CR. Tandem duplication of the FLT3 gene in acute lymphoblastic leukemia: a marker for the monitoring of minimal residual disease. Leukemia 2000;14:522-4.

6. Andersson A, Paulsson K, Lilljebjörn $H$, Lassen $C$, Strömbeck B, Heldrup J , Behrendtz $M$, J ohansson B, Fioretos T. J ohansson and T. Fioretos. FLT3 mutations in a 10 year consecutive series of 177 childhood acute leukemias and their impact on global gene expression patterns. Genes Chromosomes Cancer 2008;47:64-70.

7. Xu B, Li L, Tang J H, Zhou SY. Zhou. Detection of FLT3 gene and FLT3/ITD mutation by polymerase chain reaction-single-strand conformation polymorphism in patients with acute lymphoblastic leukemia. Di Yi J un Yi Da Xue Xue Bao 2005;25:1207-10.

8. Paietta E, Ferrando AA, Neuberg D, Bennett J M, Racevskis J, Lazarus H, Dewald G, Rowe J M, Wiernik PH, Tallman MS, Look AT. Look. Activating FLT3 mutations in CD117/KIT(+) T-cell acute lymphoblastic leukemias. Blood 2004;104:558-60.

9. Xu F, Taki T, Yang HW, Hanada R, Hongo T, Ohnishi H, Kobayashi M, Bessho F, Yanagisawa M, Hayashi Y.Hayashi. Tandem duplication of the FLT3 gene is found in acute lymphoblastic leukaemia as well as acute myeloid leukaemia but not in myelodysplastic syndrome or juvenile chronic myelogenous leukaemia in children. Br J Haematol 1999;105:155-62.

10. Sutton R, Venn NC, Tolisano J, Bahar AY, Giles J E, Ashton LJ , Teague L, Rigutto G, Waters K, Marshall GM, Haber M, Norris MD; Australian and New Zealand Children's Oncology Group. Clinical significance of minimal residual disease at day 15 and at the end of therapy in childhood acute lymphoblastic leukaemia. $\mathrm{Br}$ J Haematol 2009. 